\title{
A Review of Epitaxial Metal-Nitride Films by Polymer- Assisted Deposition
}

\author{
Hongmei Luo \\ Department of Chemical Engineering, New Mexico State University, Las Cruces, NM 88003, USA \\ Haiyan Wang \\ Department of Electrical and Computer Engineering, Texas A\&M University, College Station, TX 77843, USA \\ Guifu Zou, Eve Bauer, Thomas M. McCleskey, Anthony K. Burrell, and Quanxi Jia ${ }^{+}$
Materials Physics and Applications Division, Los Alamos National Laboratory, Los Alamos, NM 87545, USA
}

Received March 8, 2010; Accepted March 26, 2010

Polymer-assisted deposition is a chemical solution route to high quality thin films. In this process, the polymer controls the viscosity and binds metal ions, resulting in a homogeneous distribution of metal precursors in the solution and the formation of crack-free and uniform films after thermal treatment. We review our recent effort to epitaxially grow metal-nitride thin films, such as hexagonal GaN, cubic TiN, AlN, NbN, and VN, mixed-nitride $\mathrm{Ti}_{1}$. ${ }_{x} \mathrm{Al}_{x} \mathrm{~N}$, ternary nitrides tetragonal $\mathrm{SrTiN}_{2}, \mathrm{BaZrN}_{2}$, and $\mathrm{BaHfN}_{2}$, hexagonal FeMoN $\mathrm{N}_{2}$, and nanocomposite TiN-BaZrN ${ }_{2}$.

Keywords: Nitride, Film, Solution, Polymer, Deposition

\section{INTRODUCTION}

Metal-nitrides have been known to exhibit a number of important properties such as superconductivity, catalytic activity, unusual magnetic properties, and high hardness and mechanical strength [1-7]. Tremendous efforts have been devoted to epitaxially grow binary metal-nitride films such as GaN, TiN, and AlN. Among many synthesizing routes to thin films, metalorganic chemical vapor deposition (MOCVD) and molecular-beam epitaxy (MBE) are the most common techniques for the growth of epitaxial nitride films [8-23]. However, challenges still remain in obtaining high quality epitaxial nitrides. In general, the difficulty in heteroepitaxial growth of high performance nitride films lies in the large mismatches in either lattice parameters or thermal expansion coefficients between the film and the substrate [24,25].

In addition to binary nitrides, great efforts have been made in exploring ternary and complex nitrides since the 1990s [26-36]. However, the materials investigated are mostly in bulk format that were prepared by a standard high temperature "ceramic

\footnotetext{
${ }^{+}$Author to whom corresponding should be addressed: E-mail: qxjia@lanl.gov
}

method". Furthermore, these bulk ternary nitrides very often contain impurities. Thus the intrinsic physical properties of many ternary nitrides have never been well studied. Therefore, single phase epitaxial ternary and complex nitride films are desirable.

The physical vapor deposition (PVD) and chemical vapor deposition (CVD) have the common feature of requiring vacuum systems. An alternative approach for the growth of films is chemical solution deposition, which offers the advantages in terms of the cost, the setup, and the ability to coat large areas [37,38]. The fabrication of thin films by chemical solution approach involves three basic steps: (i) preparation of the chemical solution; (ii) deposition the precursor solution on the substrates by spin-coating, dip-coating, or spray-coating; and (iii) thermal treatments for removing the organic species and crystallization the precursor films to the desired materials under proper environment. Among different chemical solution techniques to thin films, such as sol-gel, metalorganic deposition (MOD), the final two steps are similar. However, the character of the solution chemistry is vital to the quality and properties of the films. In other word, the solubility of the metal precursor, the sensitivity, viscosity and 
Table 1 . The nitride films prepared by PAD.

\begin{tabular}{l|l|l|l}
\hline Materials & structure & Lattice parameters $(\mathrm{nm})$ & Ref. \\
\hline $\mathrm{GaN}$ & hexagonal & $0.3188,0.5185$ & {$[51]$} \\
$\mathrm{TiN}$ & cubic & 0.41 & {$[53]$} \\
$\mathrm{AlN}$ & cubic & 0.43 & {$[53]$} \\
$\mathrm{NbN}$ & cubic & 0.44 & {$[52]$} \\
$\mathrm{VN}$ & cubic & 0.42 & this paper \\
$\mathrm{Ti}_{1-\mathrm{x}} \mathrm{Al}_{\mathrm{x}} \mathrm{N}$ & cubic & $0.41-0.43$ & {$[53]$} \\
$\mathrm{SrTiN}_{2}$ & tetragonal & $0.388,0.77$ & {$[54]$} \\
$\mathrm{BaZrN}_{2}$ & tetragonal & $0.416,0.840$ & {$[55]$} \\
$\mathrm{BaHfN}_{2}$ & tetragonal & $0.412,0.838$ & {$[55]$} \\
$\mathrm{FeMoN}_{2}$ & hexagonal & $0.284,0.274$ & this paper \\
$\mathrm{TiN}_{-} \mathrm{BaZrN}_{2}$ & cubic-tetragonal & & this paper \\
\hline
\end{tabular}

PAD: polymer-assisted deposition.

volatility of the solvent, and the reactivity of the mixing of metal precursor and the solvent play important roles in the quality of the final films.

There have been some reports on the growth of GaN films by chemical solution deposition [39-48]. These films have been successfully used as buffer layers for the growth of GaN films using MOCVD [39]. However, the precursors used on GaN are not widely available and difficult to handle due to their air-sensitivity. In addition, the morphology of the GaN films needs further improvement as the films were very often non-continuous leading to porous or cracked surfaces. It is apparent that a general versatile chemical solution technique to prepare metal-nitride thin films needs to be developed.

Polymer-assisted deposition (PAD), a novel chemical solution technique, has been developed recently to synthesize high quality epitaxial simple and complex oxide films with desired structural and physical properties $[49,50]$. In the PAD process, stable metal-polymer solution was used as the film precursor, where the water soluble polymer not only controls the solution viscosity but also binds the metal ions to prevent the metal ions from hydrolysis and to form a homogeneous solution. The solution is air and water insensitive and stable for months and years. Recently, we have extended this technique to prepare epitaxial nitride films. For example, hexagonal GaN [51], superconducting cubic NbN [52], cubic TiN, cubic AlN, mixed $\mathrm{Ti}_{1-\mathrm{x}} \mathrm{Al}_{\mathrm{x}} \mathrm{N}$ [53], ternary tetragonal $\mathrm{SrTiN}_{2}$ [54] $\mathrm{BaZrN}_{2}$, and $\mathrm{BaHfN}_{2}$ [55] have been successfully prepared by PAD. In this review, we will summarize the nitrides prepared by PAD as shown in Table 1.

\section{EXPERIMENTS}

In the PAD process, the procedures to form nitride films comprise the formation of a homogeneous metal polymeric liquid precursor, spin-coating the precursor solution on the substrates, and the ammonolysis of the coated films in flowing ammonia gas to yield the metal nitride films. The process begins with the binding of a water soluble metal salt (such as metal nitrate, metal chloride, or metal hydroxide) to a polymer (such as polyethyleneimine [PEI]). Some metal ions bind to PEI directly such as $\mathrm{Cu}$. Some metal ions do not bind to PEI directly such as Ti, but instead bind to functionalized PEI or ethylenediaminetetraacetic acid (EDTA) to form EDTA-metal complex. The major advantage of the EDTA route is that EDTA forms stable complexes with almost all metals. The EDTA complexes further bind to the PEI via a combination of hydrogen bonding and electrostatic attraction. The metal polymeric solution is then purified using Amicon filtration. This removes all material that is of $-10,000 \mathrm{~g} / \mathrm{moL}$ or less, including unwanted anions and cations not binding with polymers. The concentration of the metal in the solution is then determined by inductively coupled plasma-atomic emission spectrometer (ICP-AES).

In detail, Ga-polymer solution, $2 \mathrm{~g}$ of gallium chloride was dissolved in $2 \mathrm{~g}$ of PEI in $10 \mathrm{~g}$ of ethanol. The final Ga concentration is $0.156 \mathrm{M}$. To prepare Ti-polymer solution, the titanium solution ( $2.5 \mathrm{~g}$ titanium tetrachloride was added slowly to a mixture of $2.5 \mathrm{~g}$ of $30 \%$ peroxide in $30 \mathrm{~mL}$ of water) was added to a solution containing $1 \mathrm{~g}$ PEI, $1 \mathrm{~g}$ EDTA and $30 \mathrm{~mL}$ water until precipitation occurred (the pH was maintained at 7.5). For the Al-polymer solution, aluminum nitrate was mixed with fluorinated PEI polymer (PEIF, prepared by slowly adding $5 \mathrm{~mL} 48 \%$ hydrofluoric acid to $10 \mathrm{~g}$ PEI in $40 \mathrm{~mL}$ water, while maintaining the $\mathrm{pH}$ at 7). Specifically, $2 \mathrm{~g}$ aluminum nitrate hydrate was added to $3 \mathrm{~g}$ PEIF in $40 \mathrm{~mL}$ water. The final concentrations were $0.408 \mathrm{M}$ for Ti and $0.201 \mathrm{M}$ for $\mathrm{Al}$. For $\mathrm{Nb}$-polymer solution, $2 \mathrm{~g}$ of $\mathrm{NbCl}_{5}$ were converted to $\mathrm{Nb}(\mathrm{OH})_{5}$ by addition of ammonium hydroxide into the solution. The $\mathrm{Nb}(\mathrm{OH})_{5}$ was then dissolved in $30 \mathrm{~mL}$ of deionized water and $7.5 \mathrm{~mL}$ of $20 \% \mathrm{HF}$. PEI was then added in and mixed. The final solution was $0.4 \mathrm{M} \mathrm{Nb}$. To prepare V solution, $2 \mathrm{~g} \mathrm{NaVO}_{3}$ was dissolved in $40 \mathrm{~mL} \mathrm{H}_{2} \mathrm{O}$ followed by adding $2 \mathrm{~g}$ PEI. For the Sr solution, $1 \mathrm{~g}$ of EDTA and $1 \mathrm{~g}$ of PEI were dissolved in $30 \mathrm{~mL}$ of water, followed by addition of $1 \mathrm{~g}$ of $\mathrm{Sr}\left(\mathrm{NO}_{3}\right)_{2}$. Using the similar process EDTA-PEI process, metal polymer solutions containing $\mathrm{Ba}, \mathrm{Zr}$, Hf, Fe, and Mo were also prepared. The final Sr, Ba, Zr, Hf, $\mathrm{Fe}$, and Mo concentrations were 0.157, 0.216, 0.101, 0.094, 0.209, and $0.376 \mathrm{M}$.

To prepare binary nitride films, the individual solution is used; to prepare mixed, ternary nitrides or composites, the precursor solution with desired stoichiometric molar ratios is mixed from the individual solutions. The precursor solution was spin-coated on (0001) sapphire $\left(\mathrm{Al}_{2} \mathrm{O}_{3}\right)$ or (001) $\mathrm{SrTiO}_{3}$ (STO) substrates at $2,000 \mathrm{rpm}$ for $30 \mathrm{~s}$. The films were then heated in forming gas $\left(4 \% \mathrm{H}_{2}\right.$ and $\left.96 \% \mathrm{~N}_{2}\right)$ at $510^{\circ} \mathrm{C}$ for 2 hours with a ramping rate of $1{ }^{\circ} \mathrm{C} / \mathrm{min}$ and then annealed in ammonia gas at $900-1,000^{\circ} \mathrm{C}$ for 2 hours with a ramping rate of $10^{\circ} \mathrm{C} / \mathrm{min}$. Films with a thickness in the range of 30-40 nm were usually obtained from one spin-coat. It should be noted that film thickness depends on the concentration of the solution by dilution with water and spincoating rate. Thicker films could be always deposited by multiple spin-coats.

X-ray diffraction (XRD) was used to characterize the crystal structure of the films. The surface morphology of the films was analyzed by scanning electron microscopy (SEM) and atomic force microscopy (AFM). The microstructure of the films was analyzed by transmission electron microscopy (TEM). Fourier Transform Infrared (FTIR) absorbance was taken using Nicolet spectrum. The composition of the film was determined by Rutherford backscattering spectrometry (RBS). The optical properties of the films were examined by ultraviolet-visible (UV-Vis) transmittance at room temperature. The electrical resistivity $(\rho)$ was measured from 5-300 K using a standard four-probe technique by a Quantum Design Physical Properties Measurement System (PPMS).

\section{RESULTS AND DISCUSSION}

\subsection{Hexagonal GaN on sapphire}

Figure 1 shows the XRD $\theta-2 \theta$ scan, rocking curve, and $\phi$-scans of a GaN film on sapphire substrate annealed in ammonia gas at $900^{\circ} \mathrm{C}$ [51]. Only (0002) peak from hexagonal GaN is observed, indicating that the film is preferentially oriented along the $c$-axis perpendicular to the substrate surface. The full width at halfmaximum (FWHM) of the (0002) rocking curve is $0.61^{\circ}$. From the $d$-spacings of the (0002) and (10 12) diffraction peaks, the lattice parameters of the epitaxial GaN film were determined to 

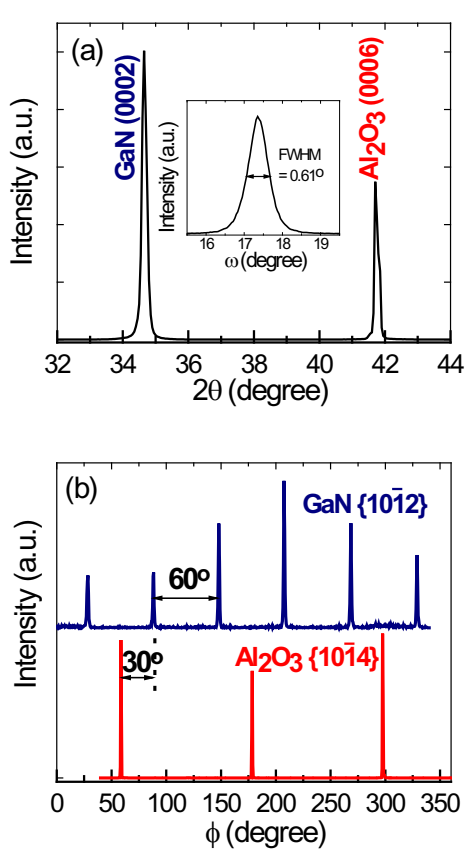

Fig. 1. X-ray diffraction patterns: (a) $\theta-2 \theta$ scan of GaN film on sapphire. Inset shows the rocking curve of (0002) reflection; (b) $\phi$-scans from (10 12$)$ reflection of GaN and (10 14$)$ reflection of sapphire (Ref. [51]).

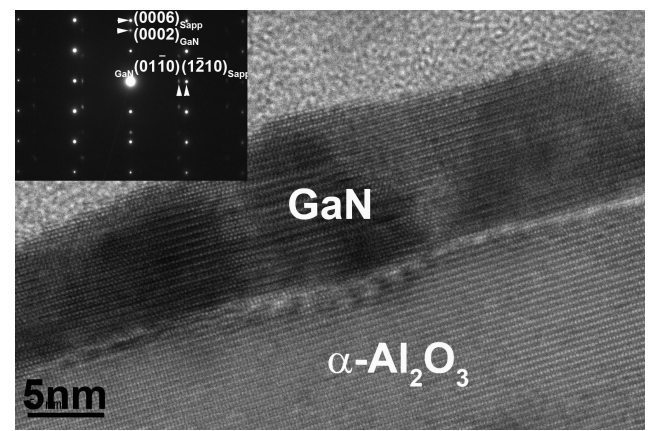

Fig. 2. Cross-section high resolution transmission electron microscopy image of a hexagonal GaN film on sapphire. Inset shows the selected area electron diffraction pattern taken from the interface.

be $a=0.317$ and $c=0.519 \mathrm{~nm}$. The in-plane orientation between the film and the substrate was determined by XRD $\phi$-scans from (10 12) GaN and (10 14) sapphire, respectively. Three peaks are observed for sapphire, while six peaks are observed for hexagonal $\mathrm{GaN}$ with $30^{\circ}$ rotation in-plane to the sapphire substrate. The epitaxial relationships between the film and the substrate can be described as $(0001)_{\mathrm{GaN}} \|(0001)_{\mathrm{Al} 2 \mathrm{O}}$ and $\left[\begin{array}{lll}11 & \overline{2} & 0\end{array}\right]_{\mathrm{GaN}} \|\left[\begin{array}{ll}10 & \overline{1} 0\end{array}\right]$ ${ }_{\mathrm{Al} 203}$, consistent with the GaN films on sapphire grown by other techniques. The films are dense and smooth with no detectable micro-cracks. Figure 2 shows the cross-section high resolution TEM (HRTEM) image of a hexagonal GaN film on sapphire. It is clear that the interface between the film and the substrate is flat. The corresponding selected area electron diffraction (SAED) pattern confirms the epitaxial growth of hexagonal GaN film on sapphire, evidenced by the distinguished diffraction dots from the film and the substrate. The epitaxial relationships between the film and the substrate deduced from the SAED pattern are consistent with the XRD analysis. The PAD grown GaN film is conductive with a room temperature resistivity of around 0.13 $\Omega \cdot \mathrm{cm}$. The room temperature Hall measurement indicates its $\mathrm{n}$ -
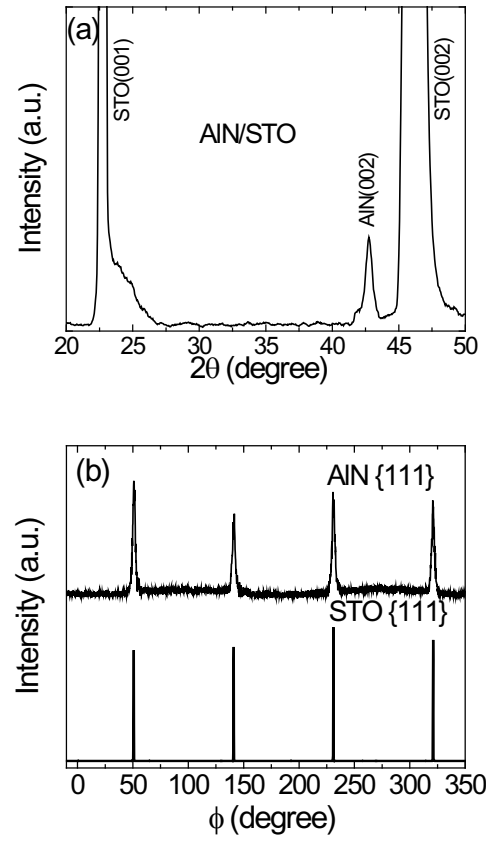

Fig. 3. X-ray diffraction patterns: (a) $\theta-2 \theta$ scan for AlN/STO; (b) $\phi$ -scans from (111) reflections of AlN and STO (Ref. [53]).

type conductivity with a carrier concentration of $2.1 \times 10^{20} \mathrm{~cm}^{-3}$ and an electron mobility of $2 \mathrm{~cm}^{2} \mathrm{~V}^{-1} \mathrm{~S}^{-1}$ [51]. The carrier mobility is still relatively low. However, the demonstration of such epitaxial films by a chemical solution approach is a big step forward for practical applications.

\subsection{Cubic TiN, NbN, VN, metastable AIN, and mix- ture $\mathrm{Ti}_{1-x} \mathrm{Al}_{\mathrm{x}} \mathrm{N}$ on $\mathrm{SrTiO}_{3}$}

The XRD patterns for TiN, AlN and mixed $\operatorname{Ti}_{1-x} \mathrm{Al}_{x} \mathrm{~N}$ films on $\mathrm{SrTiO}_{3}$ (STO) substrates are similar since the lattice parameters of cubic TiN and AlN are very close $(a=0.41-0.43 \mathrm{~nm})$ with a lattice mismatch of around 5\% with STO $(a=0.3905 \mathrm{~nm})$. Figure 3 shows the XRD results from the $\theta-2 \theta$ scan and $\phi$-scans of AlN on STO annealed at $1,000^{\circ} \mathrm{C}$ [53]. XRD results show no metal oxides exist in the nitride films. Only (002) diffraction from AlN film indicates that the film is preferentially oriented along the $c$-axis perpendicular to the substrate surface. The in-plane orientation between the films and the substrates was determined by XRD $\phi$-scans from (111) STO and (111) AlN. Four peaks with $90^{\circ}$ of separation in the $\phi$-scans indicate the epitaxial nature of the films. The epitaxial relationships can be described as (001) ${ }_{(\mathrm{Ti}, \mathrm{Al}) \mathrm{N}} \|(001)_{\text {Sто }}$ and $[111]_{(\mathrm{TT}, \mathrm{Al}) \mathrm{N}} \|[111]_{\text {SтO }}$. It is well known that the hexagonal AlN is the thermodynamically stable phase. The metastable cubic AlN phase can be stabilized and fabricated by taking advantage of the heteroepitaxy where the crystallographic order of the films can be controlled by the substrates. In addition to these binary nitrides, the solid-solution cubic $\mathrm{Ti}_{1-x} \mathrm{Al}_{\mathrm{x}} \mathrm{N}$ films on STO can be also formed by PAD by simply mixing the Ti- and Alpolymer solutions.

As expected, AlN film is insulator but has an optical transmittance greater than $75 \%$ at wavelengths in the range of 300-1,100 $\mathrm{nm}$. TiN film is highly conductive with a room temperature resistivity of around $1.9 \times 10^{-5} \Omega \cdot \mathrm{cm}$. The room-temperature resistivity increases with increasing $\mathrm{Al}$ content while the transmittance decreases with increasing Ti content in $\mathrm{Ti}_{1-x} \mathrm{Al}_{x} \mathrm{~N}$ films. Figure 4 shows the temperature dependence resistivities of TiN film annealed at $900^{\circ} \mathrm{C}$ and $\mathrm{Ti}_{1-\mathrm{x}} \mathrm{Al}_{\mathrm{x}} \mathrm{N}(\mathrm{x}=0.1$ and 0.2$)$ annealed at $1,000^{\circ} \mathrm{C}$. 


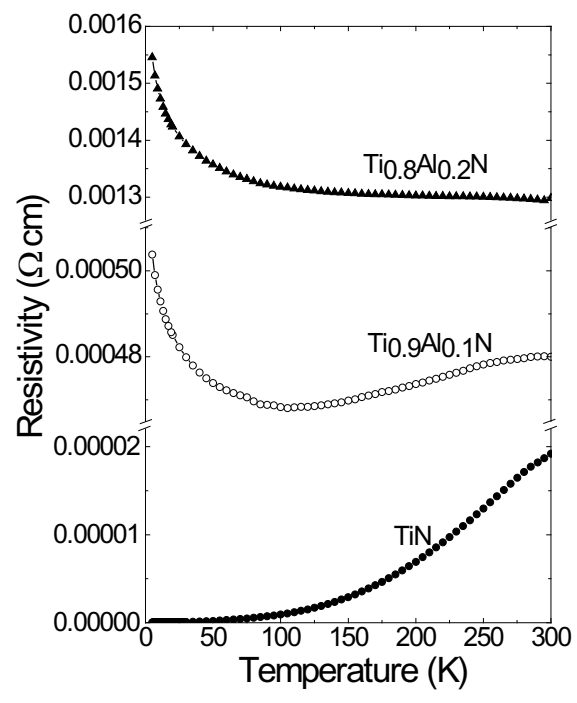

Fig. 4. Temperature dependent resistivity of a TiN film annealed at $900^{\circ} \mathrm{C}$ and $\mathrm{Ti}_{1-\mathrm{x}} \mathrm{Al}_{\mathrm{x}} \mathrm{N}\left(\mathrm{x}=0.1\right.$ and 0.2 ) films on STO annealed at $1,000^{\circ} \mathrm{C}$ (Ref. [53]).

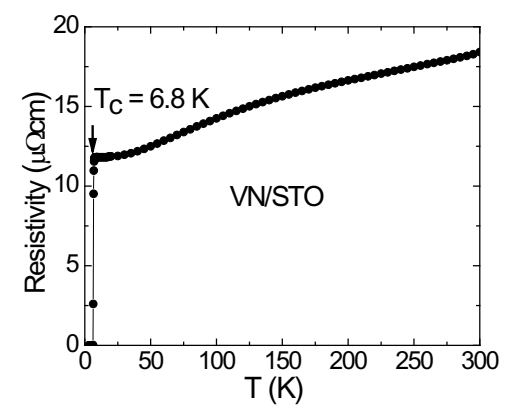

Fig. 5. Temperature dependent resistivity of a VN film on STO annealed at $900^{\circ} \mathrm{C}$.

The resistivity decreases as the decrease of temperature. On the other hand, the $\mathrm{Ti}_{0.9} \mathrm{Al}_{0.1} \mathrm{~N}$ film is metallic between $300 \mathrm{~K}$ and 100 $\mathrm{K}$ and changes to semiconductor behavior from $100 \mathrm{~K}$ to $5 \mathrm{~K}$. With further increasing $\mathrm{Al}$ content in $\mathrm{Ti}_{1-\mathrm{x}} \mathrm{Al}_{\mathrm{x}} \mathrm{N}(\mathrm{x}=0.2$ - 0.5) films, a semiconductor behavior is shown from $300 \mathrm{~K}$ to $5 \mathrm{~K}$.

The cubic $\mathrm{NbN}$ and VN prepared by PAD have the similar XRD patterns as TiN and AlN. High quality epitaxial superconducting $\mathrm{NbN}$ films with a transition temperature $\mathrm{T}_{\mathrm{c}}$ of $14 \mathrm{~K}$ have been obtained although the lattice mismatch between $\mathrm{NbN}$ and STO is $12 \%$ [52], indicating that PAD route provides an alternative approach for the preparation of epitaxial films on substrates with large lattice mismatch. We also succeeded to get superconducting epitaxial VN films on STO. Figure 5 shows the plot of resistivity vs. temperature. The resistivity increases with the temperature from $7 \mathrm{~K}$ to $300 \mathrm{~K}$, indicating a metallic behavior. A superconducting transition at temperature of $6.8 \mathrm{~K}$ is clearly seen for VN films.

\subsection{Tetragonal $\mathrm{SrTiN}_{2}, \mathrm{BaZrN}_{2}, \mathrm{BaHfN}_{2}$ on $\mathrm{SrTiO}_{3}$}

$\mathrm{SrTiN}_{2}, \mathrm{BaZrN}_{2}$, and $\mathrm{BaHfN}_{2}$ crystallize in the layered $\mathrm{KCoO}_{2}$ structure with a space group $\mathrm{P} 4 / \mathrm{nmm}$, where $\mathrm{Ba}^{2+}$ sits between layers of edge-sharing $\left[\mathrm{ZrN}_{2}\right]^{2}$ - or $\left[\mathrm{HfN}_{2}\right]^{2}$ - square pyramidal anions. The relatively small in-plane lattice mismatch between these metal-nitrides and STO makes it possible to epitaxially
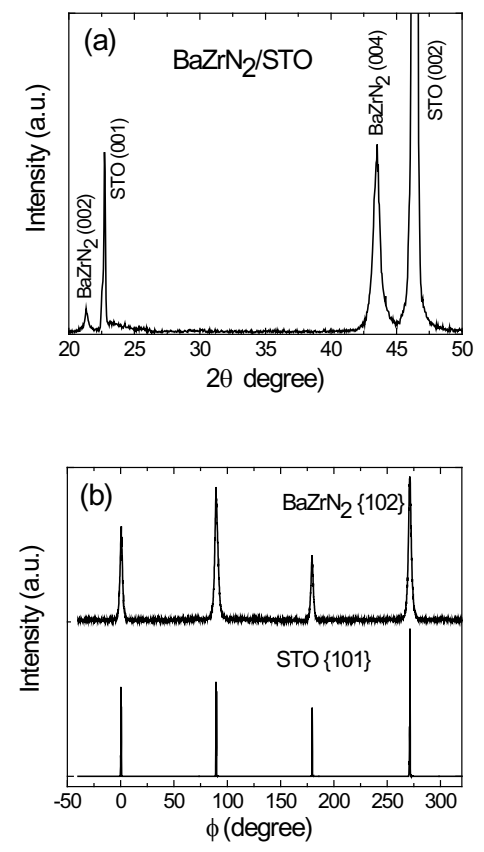

Fig. 6. X-ray diffraction patterns: (a) $\theta-2 \theta$ scan and (b) $\phi$-scans from (102) reflections of $\mathrm{BaZrN}_{2}$ and (101) of STO (Ref. [55]).

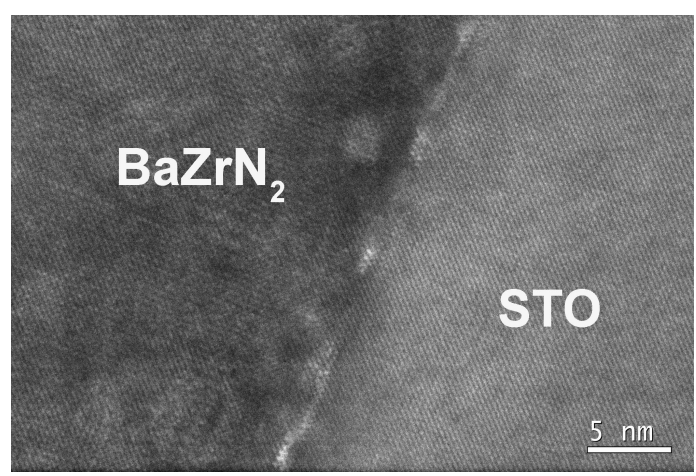

Fig. 7. Cross-section HRTEM image of a tetragonal $\mathrm{BaZrN}_{2}$ film on STO substrate.

grow these materials in film form. Figure 6 shows the XRD results from the $\theta-2 \theta$ scan and $\phi$-scan of $\mathrm{BaZrN}_{2}$ film on STO substrate annealed at $1,000^{\circ} \mathrm{C}$ for 1 hour [55]. The appearance of (002) and (004) peaks from tetragonal film together with (001) and (002) peaks from the substrate indicate that the films are preferentially oriented along the $c$-axis perpendicular to the substrate surface. It should be noted that no other detectable second phase material was observed, in contrast with ceramic ternary metalnitrides where binary nitrides are often observed. The in-plane orientation between the films and the substrates was determined by XRD $\phi$-scans from the (102) peak of $\mathrm{BaZrN}_{2}$ and (101) peak of STO, respectively. The epitaxial relationships between these films and the substrate can be generally described as $(001)_{\text {film }} \|(001)_{\text {STO }}$ and $[102]_{\text {film }} \|[101]_{\text {STо }}$. These tetragonal ternary nitride films are very dense, smooth and uniform. Figure 7 shows the HRTEM image on $\mathrm{BaZrN}_{2}$ film on STO. The interface is flat and clean.

Our ability to fabricate single phase epitaxial ternary nitride films allowed us to investigate their physical properties. $\mathrm{SrTiN}_{2}$ is a transparent semiconductor with a direct band gap of $3.65 \mathrm{eV}$ [54]. $\mathrm{BaZrN}_{2}$ and $\mathrm{BaHfN}_{2}$ films are highly metallic but no superconducting transition temperature is observed [55]. 


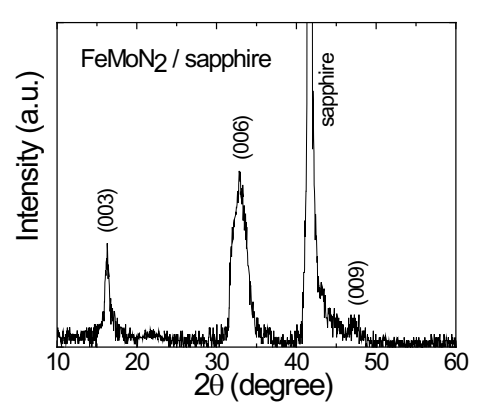

Fig. 8. X-ray diffraction pattern $\theta-2 \theta$ scan of $\mathrm{FeMoN}_{2}$ film on sapphire.

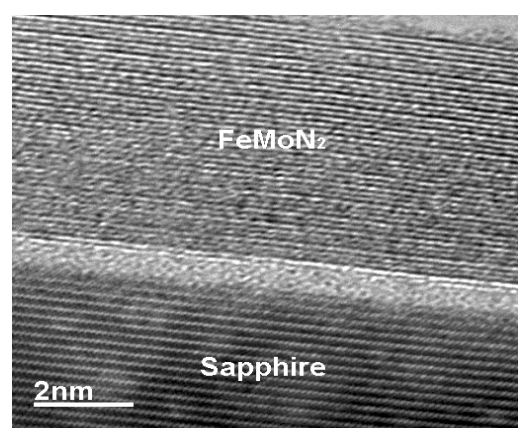

Fig. 9. Cross-section high resolution transmission electron microscopy image of a hexagonal $\mathrm{FeMoN}_{2}$ film on sapphire.

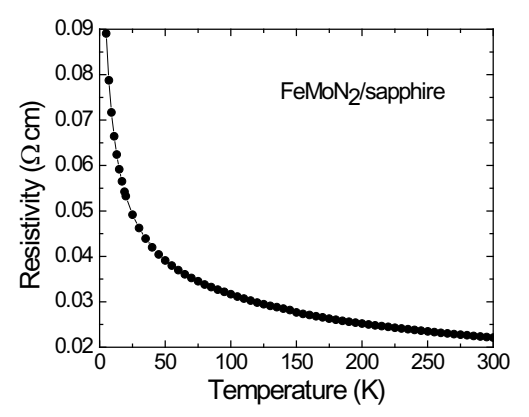

Fig. 10. Temperature dependent resistivity of a FeMoN ${ }_{2}$ film on sapphire.

\subsection{Hexagonal FeMoN ${ }_{2}$ on sapphire}

FeMoN ${ }_{2}$ crystallizes a hexagonal WC structure with lattice parameters of $\mathrm{a}=0.284$ and $\mathrm{c}=0.274 \mathrm{~nm}$. Figure 8 shows the XRD pattern of the $\mathrm{FeMoN}_{2}$ film on sapphire annealed at $1,000^{\circ} \mathrm{C}$. The $\theta-2 \theta$ scan shows the (003), (006), and (009) peaks from the film, which indicates the film is preferentially oriented along the $c$-axis perpendicular to the substrate surface. However, the in-plane orientation of the film to substrate is not observed. Figure 9 shows the cross-section HRTEM image. It is clearly seen that the film is hexagonal and epitaxial grown on sapphire. However, the film is very thin with thickness of around $5 \mathrm{~nm}$. If we increase the film thickness, the film contains binary MoN from XRD analysis, no longer a single phase of ternary nitride. Figure 10 shows the resistivity as a function of temperature curve, $\mathrm{FeMoN}_{2}$ exhibits semiconductor behavior, different from the metallic behavior reported for FeMoN $\mathrm{N}_{2}$ powder [36]. Scattering from grain boundaries and carbon or oxygen contamination at the grain boundaries in the films can all contribute to such effect.

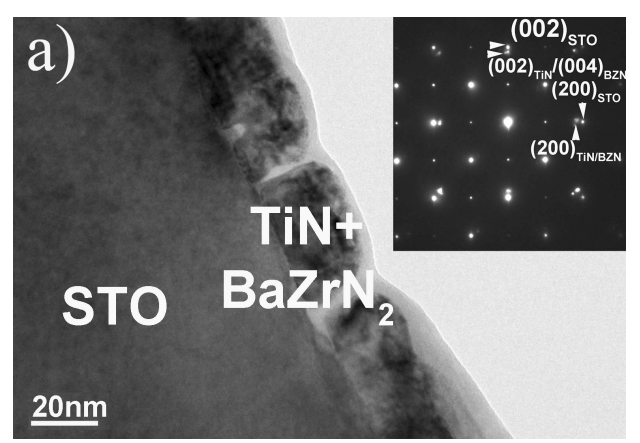

Fig. 11. (a) Cross-section high resolution transmission electron microscopy (HRTEM) images of TiN and $\mathrm{BaZrN}_{2}$ film on STO. Inset shows selected area electron diffraction pattern taken from the interface between the film and the substrate; (b) HRTEM image taken from the interface between the nanocomposite film and the substrate.

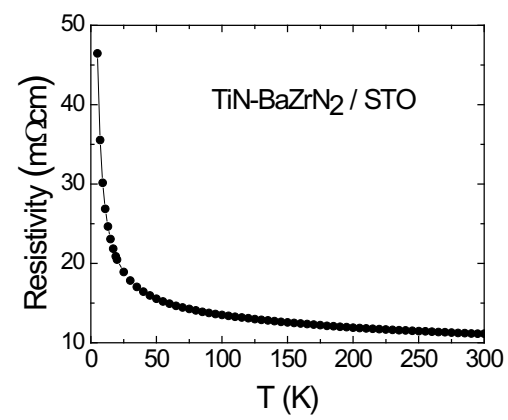

Fig. 12. Temperature dependent resistivity of a TiN-BaZrN ${ }_{2}$ composite film on STO.

It is noted that for mixed nitrides or ternary nitrides, the metal ratio and carbon and oxygen contamination have been measured with resonant RBS. The nitrides films do contain some carbon and oxygen, however, the data analysis for carbon and oxygen based on RBS are quite hard without reliable standards.

\subsection{Nitride nanocomposite $\mathrm{TiN}-\mathrm{BaZrN}_{2}$ on $\mathrm{SrTiO}_{3}$}

The PAD technique demonstrates a promising approach to synthesize single-phase ternary nitride thin films by simply mixing different metal polymer solutions. We also find that PAD can be used to prepare even complex nitride system. Here we use TiN-BaZrN ${ }_{2}$ nanocomposite as an example. To the best of our knowledge, there is no report on self-assembled nitride nanocomposite films. The precursor solution for the growth of TiN$\mathrm{BaZrN}_{2}$ nanocomposite films (molar ratio is 1:1) was prepared by mixing individual aqueous solutions of $\mathrm{Ti}, \mathrm{Ba}$, and $\mathrm{Zr}$ with polymers. Self-assembled epitaxial nanocomposite films were accomplished by annealing the precursor films in flowing ammonia at $1,000^{\circ} \mathrm{C}$ for 1 hour. The XRD results show that the TiN (002) peak is close to the $\mathrm{BaZrN}_{2}$ (004) peak. It is expected that the epitaxial relationships of the composite on substrate can be described as $(002)_{\mathrm{TiN}}\left\|(004)_{\mathrm{BZN}}\right\|(002)_{\mathrm{STO}}$ and $[101]_{\mathrm{TiN}}\left\|[102]_{\mathrm{BZN}}\right\|[101]$ sто. Figure 11 shows cross-section HRTEM image of a TiN-BaZrN film on STO substrate. The composite grows like island structure and TiN phase seems to be at the gap of $\mathrm{BaZrN}_{2}$ phase and top surface. The cross-section HRTEM image and SAED pattern taken from the interface show the epitaxial relationships between the two phases and the substrate. The reason of TiN mostly on the top surface of composites is probably due to the lower density of TiN compared with $\mathrm{BaZrN}_{2}$. It is interesting to note that the 
composite shows semiconductor behavior, as shown in Fig. 12, while both single phase TiN and $\mathrm{BaZrN}_{2}$ are highly conductive $[53,55]$. Again the grain boundary between the two phases can dominate the resistivity vs temperature behavior of the films.

\section{CONCLUSIONS}

In conclusion, the successful growth of epitaxial hexagonal GaN, cubic TiN, AlN, NbN, VN, mixed cubic $\mathrm{Ti}_{1-x} \mathrm{Al}_{\mathrm{x}} \mathrm{N}$ films, ternary nitride tetragonal $\mathrm{SrTiN}_{2}, \mathrm{BaZrN}_{2}$, BaHfN 2 , hexagonal FeMoN self-assembled nanocomposites TiN-BaZrN $\mathrm{rilm}_{2}$ films with desired structural properties indicates that PAD is an alternative approach for epitaxial nitride films. The polymer used to form the stable and homogeneous precursor solution plays an important role to form these materials.

\section{ACKNOWLEDGMENTS}

This work was supported by the U.S. Department of Energy (DOE) through the LANL/LDRD Program. H. Luo acknowledges the start-up funds from NMSU and support from New Mexico Consortium and Center for Integrated Nanotechnologies (CINT). H. Wang acknowledges NSF/DMR Ceramic Program (NSF 0709831).

\section{REFERENCES}

[1] F. J. Disalvo, Science 247, 649 (1990) [DOI: 10.1126/science.247.4943.649].

[2] N. Brese and M. O'Keeffe, Structure \& Bonding Vol. 79 (Springer Berlin, Heidelberg, 1992) p. 307. [DOI: 10.1007/BFb0036504].

[3] F. J. DiSalvo and S. J. Clarke, Curr. Opin. Solid State Mater. Sci. 1, 241 (1996) [DOI: 10.1016/s1359-0286(96)80091-x].

[4] R. Niewa and H. Jacobs, Chem. Rev. 96, 2053 (1996) [DOI: $10.1021 / \mathrm{cr} 9405157]$.

[5] M. A. Sriram, K. S. Weil, and P. N. Kumta, Appl. Organomet. Chem. 11, 163 (1997) [DOI: 10.1002/(SICI) 10990739(199702)11:2<163::AID-AOC564>3.0.CO;2-S].

[6] R. Kniep, Pure Appl. Chem. 69, 185 (1997) [DOI: 10.1351/ pac199769010185].

[7] R. Niewa and F. J. DiSalvo, Chem. Mater. 10, 2733 (1998) [DOI: $10.1021 / \mathrm{cm} 980137 \mathrm{c}]$.

[8] S. Hearne, E. Chason, J. Han, J. A. Floro, J. Figiel, J. Hunter, H. Amano, and I. S. T. Tsong, Appl. Phys. Lett. 74, 356 (1999) [DOI: 10.1063/1.123070].

[9] J. Y. Shi, L. P. Yu, Y. Z. Wang, G. Y. Zhang, and H. Zhang, Appl. Phys. Lett. 80, 2293 (2002) [DOI: 10.1063/1.1465531].

[10] G. S. Solomon, D. J. Miller, M. Ramsteiner, A. Trampert, O. Brandt, and K. H. Ploog, Appl. Phys. Lett. 87, 181912 (2005) [DOI 10.1063/1.2119408].

[11] S. Raghavan, J. Acord, and J. M. Redwing, Appl. Phys. Lett. 86, 261907 (2005) [DOI: 10.1063/1.1968436]

[12] A. P. Grzegorczyk, L. Macht, P. R. Hageman, J. L. Weyher, and P. K. Larsen, J. Cryst. Growth 273, 424 (2005) [DOI: 10.1016/ j.jcrysgro.2004.09.100].

[13] J. Narayan, P. Pant, A. Chugh, H. Choi, and J. C. C. Fan, J. Appl. Phys. 99, 054313 (2006) [DOI: 10.1063/1.2178660].

[14] A. Bchetnia, A. Touré, T. A. Lafford, Z. Benzarti, I. Halidou, M. M. Habchi, and B. El Jani, J. Cryst. Growth 308, 283 (2007) [DOI: 10.1016/j.jcrysgro.2007.09.006].

[15] K. Ueda, Y. Tsuchida, N. Hagura, F. Iskandar, K. Okuyama, and Y. Endo, Appl. Phys. Lett. 92, 101101 (2008) [DOI: 10.1063/1.2891067]

[16] X. Q. Shen, H. Matsuhata, and H. Okumura, Appl. Phys. Lett.
86, 021912 (2005) [DOI: 10.1063/1.1849836].

[17] D. Cherns, L. Meshi, I. Griffiths, S. Khongphetsak, S. V. Novikov, N. Farley, R. P. Campion, and C. T. Foxon, Appl. Phys. Lett. 92, 121902 (2008) [DOI: 10.1063/1.2899944].

[18] P. K. Kuo, G. W. Auner, and Z. L. Wu, Thin Solid Films 253, 223 (1994) [DOI: 10.1016/0040-6090(94)90324-7].

[19] A. Sidorenko, H. Peisert, H. Neumann, and T. Chassé, Appl. Surf. Sci. 252, 7671 (2006) [DOI: 10.1016/j.apsusc.2006.03.053].

[20] J. W. Gerlach, A. Hofmann, T. Höche, F. Frost, B. Rauschenbach, and G. Benndorf, Appl. Phys. Lett. 88, 011902 (2006) [DOI: 10.1063/1.2159100].

[21] K. Kusakabe, S. Ando, and K. Ohkawa, J. Cryst. Growth 298, 293 (2007) [DOI: 10.1016/j.jcrysgro.2006.10.095].

[22] S. B. S. Heil, E. Langereis, F. Roozeboom, M. C. M. Van De Sanden, and W. M. M. Kessels, J. Electrochem. Soc. 153(2006) [DOI: 10.1149/1.2344843].

[23] Q. S. Paduano, D. W. Weyburne, J. Jasinski, and Z. LilientalWeber, J. Cryst. Growth 261, 259 (2004) [DOI: 10.1016/ j.jcrysgro.2003.11.017].

[24] S. Strite and H. Morkoc, J. Vac. Sci. Technol. B 10, 1237 (1992) [DOI: 10.1116/1.585897].

[25] J. Jasinski, Phys. Stat. Sol. C 2, 941 (2005) [DOI: 10.1002/ pssc.200590002].

[26] D. H. Gregory, M. G. Barker, P. P. Edwards, and D. J. Siddons, Inorg. Chem. 37, 3775 (1998) [DOI: 10.1021/ic971556z].

[27] G. Farault, R. Gautier, C. F. Baker, A. Bowman, and D. H. Gregory, Chem. Mater. 15, 3922 (2003) [DOI: 10.1021/cm034502y].

[28] J. L. Hunting, M. M. Szymanski, P. E. Johnson, C. Brenhin Kellar, and F. J. DiSalvo, J. Solid State Chem. 180, 31 (2007) [DOI: 10.1016/j.jssc.2006.09.018].

[29] A. Gomathi, Mater. Res. Bull. 42, 870 (2007) [DOI: 10.1016/ j.materresbull.2006.08.021].

[30] D. McKay, J. S. J. Hargreaves, J. L. Rico, J. L. Rivera, and X. L. Sun, J. Solid State Chem. 181, 325 (2008) [DOI: 10.1016/ j.jssc.2007.12.001].

[31] O. Seeger, M. Hofmann, J. Strahle, J. P. Laval, and B. Frit, Z. Anorg. Allg. Chem. 620, 2008 (1994) [DOI: 10.1002/ zaac.19946201129].

[32] D. H. Gregory, M. G. Barker, P. P. Edwards, M. Slaski, and D. J. Siddons, J. Solid State Chem. 137, 62 (1998) [DOI: 10.1006/ jssc.1997.7686].

[33] D. H. Gregory, P. M. O’Meara, A. G. Gordon, D. J. Siddons, A. J. Blake, M. G. Barker, T. A. Hamor, and P. P. Edwards, J. Alloys Compd. 317-318, 237 (2001) [DOI: 10.1016/s09258388(00)01340-2].

[34] T. J. Prior, S. E. Oldham, V. J. Couper, and P. D. Battle, Chem. Mater. 17, 1867 (2005) [DOI: 10.1021/cm047859q].

[35] Z. Stoeva, B. Jager, R. Gomez, S. Messaoudi, M. B. Yahia, X. Rocquefelte, G. B. Hix, W. Wolf, J. J. Titman, R. Gautier, P. Herzig, and D. H. Gregory, J. Am. Chem. Soc. 129, 1912 (2007) [DOI: 10.1021/ja063208e].

[36] R. N. Panda and N. S. Gajbhiye, J. Cryst. Growth 191, 92 (1998) [DOI: 10.1016/s0022-0248(98)00011-6].

[37] F. F. Lange, Science 273, 903 (1996) [DOI: 10.1126/science.273.5277.903].

[38] R. W. Schwartz, Chem. Mater. 9, 2325 (1997) [DOI: 10.1021/ cm970286f].

[39] M. Puchinger, T. Wagner, P. Fini, D. Kisailus, U. Beck, J. Bill, F. Aldinger, E. Arzt, and F. F. Lange, J. Cryst. Growth 233, 57 (2001) [DOI: 10.1016/s0022-0248(01)01495-6].

[40] D. Rodewald, J. Bill, U. Beck, M. Puchinger, T. Wagner, A. Greiner, and F. Aldinger, Adv. Mater. 11, 1502 (1999) [DOI: 10.1002/ (sici)1521-4095(199912)11:18<1502::aid-adma1502>3.0.co;2-u].

[41] M. Puchinger, T. Wagner, D. Rodewald, J. Bill, F. Aldinger, and F. F. Lange, J. Cryst. Growth 208, 153 (2000) [DOI: 10.1016/s00220248(99)00416-9].

[42] M. Puchinger, D. J. Kisailus, F. F. Lange, and T. Wagner, J. Cryst. Growth 245, 219 (2002) [DOI: 10.1016/s0022-0248(02)01712-8]. 
[43] H. Parala, A. Devi, A. Wohlfart, M. Winter, and R. A. Fischer, Adv. Funct. Mater. 11, 224 (2001) [DOI: 10.1002 /1616-3028(200106)11:3<224::aid-adfm224>3.0.co;2-4].

[44] D. Kisailus, J. H. Choi, and F. F. Lange, J. Mater. Res. 17, 2540 (2002) [DOI: 10.1557/JMR.2002.0369].

[45] T. P. Niesen, M. Puchinger, P. Gerstel, D. Rodewald, J. Wolff, T. Wagner, J. Bill, and F. Aldinger, Mater. Chem. Phys. 73, 301 (2002) [DOI: 10.1016/s0254-0584(01)00393-5].

[46] K. Sardar, A. R. Raju, and G. N. Subbanna, Solid State Commun 125, 355 (2003) [DOI: 10.1016/s0038-1098(02)00810-4].

[47] A. L. Hector, Chem. Soc. Rev. 36, 1745 (2007) [DOI: 10.1039/ b608838b].

[48] G. Sinha, D. Ganguli, and S. Chaudhuri, J. Colloid Interface Sci. 319, 123 (2008) [DOI: 10.1016/j.jcis.2007.11.014].

[49] Q. X. Jia, T. M. McCleskey, A. K. Burrell, Y. Lin, G. E. Collis, H. Wang, A. D. Q. Li, and S. R. Foltyn, Nature Materials 3, 529 (2004) [DOI: 10.1038/nmat1163].

[50] A. K. Burrell, T. Mark McCleskey, and Q. X. Jia, Chem. Commun., 1271 (2008) [DOI: 10.1039/b712910f].
[51] H. Luo, Y. Lin, H. Wang, C. Y. Chou, N. A. Suvorova, M. E. Hawley, A. H. Mueller, F. Ronning, E. Bauer, A. K. Burrell, M. McCieskey, and Q. X. Jia, J. Phys. Chem. C 112, 20535 (2008) [DOI: 10.1021/jp807793p].

[52] G. Zou, M. Jain, H. Zhou, H. Luo, S. A. Baily, L. Civale, E. Bauer, T. M. McCleskey, A. K. Burrell, and Q. Jia, Chem. Commun., 6022 (2008) [DOI: 10.1039/b815066d].

[53] H. Luo, Y. Lin, H. Wang, J. H. Lee, N. A. Suvorova, A. H. Mueller, A. K. Burrell, T. M. McCleskey, E. Bauer, I. O. Usov, M. E. Hawley, T. G. Holesinger, and Q. Jia, Adv. Mater. 21, 193 (2009) [DOI: 10.1002/adma.200801959].

[54] H. Luo, H. Wang, Z. Bi, D. M. Feldmann, Y. Wang, A. K. Burrell, T. M. McCleskey, E. Bauer, M. E. Hawley, and Q. Jia, J. Am. Chem. Soc. 130, 15224 (2008) [DOI: 10.1021/ja803544c].

[55] H. Luo, H. Wang, Z. Bi, G. Zou, T. M. McCleskey, A. K. Burrell, E. Bauer, M. E. Hawley, Y. Wang, and Q. Jia, Angewandte Chemie - International Edition 48, 1490 (2009) [DOI: 10.1002/ anie.200805394]. 